\title{
Importance Electronic Payment System for Economy
}

\author{
Abdulmunm Saadi \\ Phd.candidate \\ DOI: 10.29322/IJSRP.11.08.2021.p11666 \\ http://dx.doi.org/10.29322/IJSRP.11.08.2021.p11666
}

\begin{abstract}
Adjusting the newly termed circumstances and challenges, electronic business goes through significant changes. In order for financial speculation to adapt its range of products and services through new distribution channels, new modern information technologies in the field of electronic payment are used. Products and services are provided with electronic payment that provides customer service users with a daily communication with a bank, special channel of electronic posting. There is a large number of benefits that the application of information technologies in the field of electronic business such as cost reduction, increase efficiency, innovation, mobility, etc.
\end{abstract}

Index Terms- Electronic business, electronic payment, information technology, electronic banking, economy

\section{INTRODUCTION}

$\mathrm{T}$ he first payment cards or so-called "Plastic money" appeared in half of the twentieth century. Frank McNamara (Frank Mek Namara) has designed a new way of payment in the form of a cardboard identification card in 1949. Namely, the card guaranteed the user's creditworthiness, and payment to the sales place where the purchase guaranteed a company that assigned consumption limit based on the user's creditworthiness. ${ }^{1}$

\section{CARDS}

Payment cards provide the payment of various goods and services, as well as raising cash at ATMs and banks without the user to be able to lose money or to face different payment procedures and money transfer (especially if Payment performs abroad). ${ }^{2}$ The cards are used to pay for goods and services, as well as to collect or draw cash.

Credit cards, what do we know today have emerged in the United States in the late 1960s, so that it would only be expanded around the world later. Debit cards are more recently and developing the fastest in the UK. There are different definitions of payment cards, so we list some of them.

\footnotetext{
${ }^{1}$ Payment cards, educational material for police and judicial representatives, Serbian Chamber of Commerce, p. 7.

${ }^{2}$ Uroš T., Electronic Banking, Belgrade Business School
}

https://www.ucg.ac.me/skladiste/blog_21970/objava_32768/fajlo

vi/Elektronsko\%20bankarstvo.pdf

${ }^{4}$ Pavlović, Z., (2006). Criminal Protection of Payment Cards, in:

New solutions in criminal legislation and previous experiences in
Payment cards are basically small pieces of plastic containing an identification, allowing the person to which the card is belonging to buy goods or services to the expenditure of hers or his account. Another canvas card define as a specific instrument of non-cash payment method issued by the Bank, a trade or specialized organization that allows its owner to settle its payment obligations to the seller's goods or exercise. ${ }^{3}$

\section{MODERN WAY OF PAYMENT}

Payment cards are a modern way of payment where the card user assumes an obligation to pay a certain amount of money, and the seller of goods or services is entitled to collect from the card issuer. The payment card is not the value paper that provides a replacement for money, such as e.g. characterized by a check, because the card always remains in the hands of the user. ${ }^{4}$

Nowadays there are two types of cards, and these are debit and credit. Credit pay after the card are based on the payment system for the obligations collected in one, contracted time, on the day of maturity. Unlike the check or debit cards, the user does not have money in credit cards, to a specific limit at the time of purchase, but at the time of maturity of the obligation to pay the bill set by card organization. ${ }^{5}$ In essence, the Bank for renting a credit card to the client agrees to give a loan. At the time of using a credit card on the client's account does not have to be money.

Debit card (known and called ATM card) is a card issued by the Bank to own a current or foreign exchange account so that with its funds could be disposed of regardless of the bank's branch office. ${ }^{6}$ These cards are used only in trading shops that are equipped with ATMs or POS terminals mainly in retail stores, gas stations, restaurants, and debit cards can only be used to the client's deposit account. ${ }^{7}$

In addition to the listed two types of cards, there are also prepaid (prepaid) cards, which contain a computer chip that inserts the amount of money from the card owner account or cash billing from it. A certain amount of money is deposited on such cards

their implementation, Zlatibor, Association of Criminal Law and Criminology, p. 164

${ }^{5}$ Ibid

${ }^{6}$ Jelenski, M., Šupristina, M., Budiša, J., (2013) .Chiminal pay cards (identity theft, counterfeiting and criminal cards), police and security, 22 (3), p. 373.

${ }^{7}$ Milojevic, D., (2003). Lexicon of banking - with professional terminology in German and English. Belgrade: D. Milojevic

This publication is licensed under Creative Commons Attribution CC BY 
available to the client. There are monotonium and multipurpose pre-paid cards. ${ }^{8}$

Also, the following types of payment cards according to different criteria should also be stated:

1. According to the payment card appearance, they can be smooth and embossed;

2. According to the payment card, the payment cards with a magnetic record or payment card with chip can be: Payment cards;

3. According to the application of payment cards, international valid payment cards, national and corporate can be: international and corporate. ${ }^{9}$

\section{Digital WALLETS}

Nowadays, everything is more often heard the term "digital wallet". The digital wallet is nothing but a wallet in the so-called digital form. It contains everything that contains every other wallet when we speak the financial part of that wallet.

"Digital wallet (e-wallet) refers to an electronic device or network service that allows individuals to electronic transactions. An individual's bank account can also be connected to a digital wallet. The digital wallet also contains a software and information component. The software provides security and encryption for personal data and for actual transactions. They can also have a driver's license, a health card, loyalty card and other personal documents stored on the phone. "10

Some of the most important features of digital wallet are:

- To confirm the identity of users through digital certificates or other encrypted methods.

- To store and convey a monetary value.

- To ensure the payment process from the customer to the seller.

Currently, there are two basic categories of digital wallets, as follows:

- Client-based Digital Wallet (digital wallet Located on a digital wallet Located on the desktop desktop client in the client) - presents software applications that users install on their computers. These wallets offer customers the convenience of automatic fulfillment of forms in an online store. Sellers install software on their servers, using which they are sending the information that sends a digital wallet.

- $\quad$ Server-based Digital digital wallet (digital wallet Located on a digital wallet Located on a remote server server) These digital wallets are software service / product for identity and payment, which are sold to financial institutions. Financial institutions sell these systems further on the market sellers present on the Internet, directly or as part of the financial services package. The sellers of these wallets can also provide the infrastructure

\footnotetext{
${ }^{8}$ Tamara, U., (2008). Electronic banking, Belgrade, Belgrade Business School

${ }^{9}$ Babović, S., (2015). The crime of falsification and abuse of payment cards in the legislation of the Republic of Serbia and the countries of the Western Balkans, the right - theory and practice 32 (7-9), p. 64
}

necessary for the payment process as well as the service of the wallet.

In addition to the above, there are two other types of digital wallets:

- "Digital Wallet with a pre-updated amount of funds: Subscribed digital wallet is a wallet on which e-money is pre-paid and can be used as a cash alternative. Users of this wallet must be supplemented before payment of online transactions by adding funds via cards or alternative payment methods. The amount found in the ewallet can be used to pay online and mobile transactions.

- Pass-through digital wallet: Pass-through digital wallet is the one with which e-wallet confirms the user's identity (authentifies it), but the payment is performed via a connected payment system, such as a bank account, credit, debit or pre-refilled card. The e-wallet user does not use the funds found in the wallet, but at the time of payment, one of the "saved" payment methods to complete the payment process. "11

The digital wallet reduces the need to carry a physical wallet, because payments are made in a safe and compact way.

\section{BIOMETRIC PAYMENT SYSTEMS}

Biometric identity confirmation includes scanning fingerprint on the device, the scan of the cornea, ie. the eye or scan of the face depending on what the user's device supports. "Identification of identities today is one of the basic starting points when performing various administrative activities. Under identity of the person, we mean the sum of general and personal signs characteristic of one person, through which it differs from other persons and who can certainly be identified, ie identifiable. "12

Biometric systems automatically performs the individual identification and provider based on psychological and behavioral characteristics, exclusively through computer technology, which compares the individual templates in real time with registered data. Like, devices that recognize facials, hands, fingers, signs or fingerprints. Depending on the needs, the biometric system can work in two ways:

- $\quad$ Authentication - authentication, the system confirms or rejects identity by comparing biometric characteristics with a template previously saved in the base. If someone wants to present their identity and be identified, attaches its biometric template contained on the card. The system then compares data from the card, with the previously recorded data of the person who has attached the card. If both match, that person was received, otherwise rejected. This type of recognition is also called positive recognition.

\footnotetext{
${ }^{10}$ https://en.wikipedia.org/wiki/Digital_wallet

${ }^{11}$ https://www.kliker.ba/aktuelno/11072018/ta-je-enovcanik\#_ftn1

${ }^{12}$ Working group, "project integrated automated system for personalization of electronic identification identification documents ", MUP 2002-2004. years.
} 
- Identification - Identity recognition, the system compares the biometric characteristics of the person with templates stored in the base to find the largest match. On that occasion, a comparison of type is performed towards much The system simply scans that person, and checks whether its data are entered in the system, and if they are allowed access. This is called yet negative recognition. The goal is to prevent one person from using more identities. "13

Biometry-based technology can measure different biometric characteristics. The process of taking data consists of:

- acquisitions of biometric data using biometric scanner;

- processing of data taken and preparations for enrollment in the base of biometric data;

- data enrollment in the database, a central database or enrollment on the local portable device (Smart card);

The recognition process consists of:

- Scanning of biometric data,

- processing biometric data and preparations for comparison with previously taken data,

- Compare data taken with data previously enrolled. "14

\section{MICRO-PAYMENT}

"Micro-payments are electronic payments of small values that are specially designed for electronic trade on the Internet, ie for small value payments. Microwaves generally defrosted commercial transactions whose individual value is below five dollars. Microwaves are replacement for small money. Electronic money has a number of characteristics that make it far easier to manipulate from cash. "15 Savings concerning technological nature, which are achieved by applying a microweption system, due to the fact that the business model is based on a pre-deposited amount of money on the bank account, the need for certificates from the bank or other financial institutions that manages micropayment system. The most famous system of this species is a MiliCent.

\section{ELECTRONIC CHECKS}

Electronics check is "Electronic version or representative of the paper check. It was founded on the same legal framework, containing the same information as a paper check, can be connected to ungraded information, can be used in any transaction where paper check is used, increasing function and features in the case of the check amount and It reduces the use of pepper checks. ${ }^{16}$ "The electronic check is based on digital signature or series, on a suggestive hardware, bank and business practice and finally on FSMP (Financial Services Markup Language). It uses the following security mechanisms: Authenticity, public key of

\footnotetext{
${ }^{13}$ http://www.infotech.org.rs/blog/wpcontent/uploads/radovi2013/081.pdf

${ }^{14} \mathrm{http}$ ://www.infotech.org.rs/blog/wpcontent/uploads/radovi2013/081.pdf
}

cryptography, digital signature, surveillance certificate, double dortium and eventually encryption.

\section{EBPP (ELECTRONIC BILLING PRESENTMENT AND PAYMENT)}

Electronic Payment and Account Presentation (EBPP) or English Electronic Billing Presentment and Payment is a process that companies use for electronic payments through systems such as internet, direct dialing and ATM devices. Today, EBPP has become a key component of internet banking in many financial institutions. Other industries - including insurance suppliers, telecommunications companies and utilities - also depend on EBPP services.

The EBPP occurs in two forms:

- Direct account calculation - Direct charging is an electronic billing offered by a company that provides goods or service.

- The bank's aggregate - the model of bank aggregates or account consolidation allows customers to pay accounts to many different companies through a single portal. That is, the service collects various payments from customers and distributes any payment to the appropriate company.

Some newer EBPP products include functions such as secure email delivery, stored payment and automatic payment information. Many large banks offer payments and account services electronically as part of its banking system on a global network. In general, Internet banking, which is sometimes called "web banking", allows users to perform financial transactions over the Internet. Specifically, the Bank offers customers the possibility of deposits, raising funds, transfer between accounts and other traditional services, as well as payments through online accounts, such as EBPP.

\section{MOBILE BANKING}

Mobile banking gives the possibility of banks to provide customers with personalized information based on real-time information and increase loyalty to banking services. Simple, "Mobile Banking is a service that allows banks to make part of its financial services available to users. This achieves higher quality services, lower costs and for the bank and clients and increased customer satisfaction. Mobile banking enables the execution of transactions through portable computers, digital personal organizers and mobile phones.

When it comes to M-banking, banks, of all financial institutions, were the first ones offered services in this domain.

15

https://www.academia.edu/41819096/Pojam_elektronskog_bank arstva

16 Tamara Djogić, Contemporary Tendencies in the field of electronic banking, Faculty of Ecology, University of Business Engineering and Management, Banja Luka, 2014, Page 11 
Statistics show that in 1999, 90\% of banks in Europe in Europe in its offer had some form of mobile banking. "17

Mobile banking is not only in the function of paying bills, but also has many other different functions and opportunities, such as:

- insight into the balance on all accounts in one bank,

- Insight into the turnover by these accounts,

- Records of all transactions made by M-Banking,

- Different payments (according to loans, for communal services, etc.)

- Order checks,

- Capelling of foreign currency and dr.

\section{MOBILE PAYMENT MODELS}

The most important aspect of mobile banking are mobile payments that are still in the development phase. There are several different initiatives that apply with more or less successes on the market:

- $\quad$ "The first attempts to the mobile payment were based on a combination of banking pay cards and mobile phones technology. Payment procedure is as follows: The user is ordered by the mobile phone or service, and then the SMS message receives information about successfully implemented order. After that, the user enters the payment card into the reader and realizes the payment transaction while entering the transaction authorization code. The lack of this payment model is the fact that the user must own two devices to prevent the transaction uninterrupted: Moblins phone and card reader.

- Using SMS messages as a billing system in general, applies with a lot of success in the collection of different categories of services and goods such as parking, access to web sites, tone collection, mobile phones, etc. In this payment model, the mobile telephony operator has the role of an institution that performs clearing between participants in the transaction, with the borrowing of mobile telephony services. This payment model is far more attractive for application from the model based on payment cards and mobile phones, because it allows merchants and clients to perform transactions by applying existing infrastructure

- Payment models based on users use their mobile devices, which contain a Smart card for payment issued by the bank. This payment method is used to pay for those costs that would otherwise be paid by finished money. Thus, mobilini apparatus "equipped cards issued from banks can use for various transactions at ATMs (Cash Checking, Raising, Raising Automatics (food, refreshing drinks, various types of tickets).

- The progress of mobile technology provides their possibility to owners that very easily, using mobile phones access e-banking systems of their banks and to perform bank transactions unhindered. This segment of the mobile pay market has the largest share and the greatest potential for future growth. The expansion of this model of mobile payments was particularly contributed by the phenomenon of Android operating system.

\section{CONCLUSION}

There is a large number of benefits that the application of information technologies in the field of electronic business such as cost reduction, increase efficiency, innovation, mobility, etc. However, as opposed to the listed advantages, shortcomings that primarily include providing the higher security of customer data. Backs, next to clients, bear the risk of electronic business. Due to abuse, poor protection on the Internet, lack of privacy, financial institutions must develop a strategy for solving problems in the application of modern information technologies in this area.

\section{REFERENCES}

[1] G. O. Young, "Synthetic structure of industrial plastics (Book style with paper title and editor)," in Plastics, 2nd ed. vol. 3, J. Peters, Ed. New York: McGraw-Hill, 1964, pp. 15-64.

[2] W.-K. Chen, Linear Networks and Systems (Book style). Belmont, CA: Wadsworth, 1993, pp. 123-135.

[3] H. Poor, An Introduction to Signal Detection and Estimation. New York: Springer-Verlag, 1985, ch. 4.

[4] B. Smith, "An approach to graphs of linear forms (Unpublished work style)," unpublished.

[5] E. H. Miller, "A note on reflector arrays (Periodical style-Accepted for publication)," IEEE Trans. Antennas Propagat., to be published.

[6] J. Wang, "Fundamentals of erbium-doped fiber amplifiers arrays (Periodical style-Submitted for publication)," IEEE J. Quantum Electron., submitted for publication.

\section{AUTHORS}

First Author - Abdulmunm Saadi Phd.candidate
${ }^{17}$ Dr. Vladimir Simović, Electronic Business, Volikova Strukon's Information Technology Studies, Belgrade, 2013, page 76-77 